\title{
Development of Adaptive Clothing for People with Disabilities
}

\author{
Leysan M. TUKHBATULLINA \\ Ph.D. (in Technical Sciences) \\ Associate Professor \\ Department of Design \\ Faculty of Design and Software Engineering \\ Kazan National Research University \\ 68, Karl Marx Str., Kazan, 420111, Russia \\ tuleissan@mail.ru \\ Lyudmila A. SAFINA \\ Ph.D. (in Technical Sciences) \\ Associate Professor \\ Department of Design \\ Faculty of Design and Software Engineering \\ Kazan National Research University \\ 68, Karl Marx Str., Kazan, 420111, Russia \\ lsafina@mail.ru
Aisylu I. VILDANOVA
Head of Laboratory
Department of Design \\ Faculty of Design and Software Engineering \\ Kazan National Research University \\ 68, Karl Marx Str., Kazan, 420111, Russia \\ dizainkstu@mail.ru
}

\begin{abstract}
The article discusses the relevance of the problem of improving the quality of life of people with disabilities. The concept of "disability" is studied, the classification of existing disabled groups is considered, which identifies the groups and contributes to the study of private groups in need of special adaptive clothing. One of the important aspects of the article is the study of the requirements for clothing for people with disabilities and the factors that cause the greatest inconvenience when wearing clothes, due to a sedentary lifestyle. The study of this topic made it possible to identify ways to solve these problems by introducing structural and technological elements that contribute to a more comfortable stay for persons with disabilities, in particular, wheelchair users. The author's proposal is the use of the technology of inflatable elements in the development of a set of adaptive clothing for disabled people, which allows you to remove part of the physical load from the spine, create an orthopedic base for sitting in a wheelchair, and provide additional heat and wind protection.
\end{abstract}

Keywords: people with disabilities; clothing for people with disabilities; adaptive clothing; constructive and technological elements; inflatable technology.

\section{Introduction}


The problem of improving the quality of life is a problem of national and international interest. It is an inevitable social responsibility to create equal opportunities for people with disabilities, prevent any deliberate or unintentional discrimination they face, and apply affirmative action, if necessary, to improve their living standards and ensure that they have an equal share in social development as productive members of society.

A disability is any kind of restriction or inability to perform a certain activity that falls within an interval that is considered «normal» for a person. Disability is characterized by deficiencies or excesses in activities or behavior that are usually expected of a person; they can be temporary or permanent, reversible or irreversible, progressive or regressive.

Disability is a consequence of impairments that can be physical, cognitive, mental, sensory, emotional, developmental, or their various combinations. Disability can be present from birth or occur during a person's life. It is a general term covering impairments, activity limitations and participation limitations, which includes the concepts of the degree of disability and their classification (Bolgitskaya, 2014).

This classification allows you to determine those groups that need special clothing, additional devices for organizing their environment and adapting to it. So, the third group of disabilities implies only a slight impairment of coordination and movements, which minimizes the need to make any changes in the design or technology of creating clothes, in contrast to the second and first groups (Table 1).

Table 1. Classification of existing groups and criteria for disability

\begin{tabular}{|c|c|c|}
\hline First group & Second group & Third group \\
\hline $\begin{array}{l}\text { Complete loss of ability to work. } \\
\text { Important body functions are } \\
\text { critically impaired. Impossibility of } \\
\text { self-service. Life requires constant } \\
\text { outside help. }\end{array}$ & $\begin{array}{l}\text { It is impossible to work normally. } \\
\text { The work requires special } \\
\text { equipment or conditions. } \\
\text { Functional dysfunctions are } \\
\text { significant, but constant care is not } \\
\text { required. }\end{array}$ & $\begin{array}{l}\text { The ability to work is preserved, } \\
\text { but health does not allow } \\
\text { performing work according to the } \\
\text { previous qualifications, or } \\
\text { continuation of the activity } \\
\text { requires a reduction in the volume } \\
\text { of work. }\end{array}$ \\
\hline
\end{tabular}

Currently, the assignment of a disabled person to a particular category of disability is determined on the basis of classifications of the motor activity of disabled people (taking into account the preservation or reduction of the degree of their motor abilities), social and professional employment, the need for technical means of rehabilitation, the need for additional help or care (Bolgitskaya, 2014)

The International Classification of Functioning, Disability and Health defines the following types of disability:

1) Statodynamic - the motor abilities of the head, body, limbs are impaired, and there is also an inadequate coordination of movement.

2) Mental - disorders of intellectual abilities, memory, conscious perception of reality, sound thinking.

3) Linguistic and speech - violations of oral speech (stuttering), writing (difficulty in mastering writing techniques) and the presence of verbal or non-verbal speech.

4) Violations of the circulatory system, metabolism, as well as parts of the digestive and respiratory organs. 
5) Physical changes - significant changes in the configuration of body parts (head, body, limbs), leading to ugly forms. This includes the presence of unnatural holes in the urinary, respiratory system, as well as unacceptable body sizes for a healthy person.

6) Sensory - poor functioning of the organs of hearing, sight, smell and improper sensitivity to pain and temperature.

This division into types helps to consider special cases, without limiting them into one category. Since each category requires a special approach to meet specific needs.

As for the functioning of the «disabled person - clothes» system, it is characterized by a violation of a long-term stereotype, which is caused by a disease or defect in the patient's musculoskeletal system, which makes it difficult or impossible for the disabled person to perform the necessary actions when using clothing (Krasnova, 2011). It is these circumstances that lead him to partial or complete dependence on the services of others. Clothes specially designed for people with disabilities should: provide greater freedom and independence in wearing, conform to an aesthetic point of view, offer psychological benefits, and help socially integrate the person wearing it. In addition, clothing should not impede a person's mobility and should allow maximum use of the chest and upper limbs, it should be durable, have a low level of electrostatic charge, be absorbent and comfortable, have so-called "rehabilitation functions" and, finally, be useful for the wearer. both from a physical and psychological point of view (Safina, Tukhbatullina, Khammatova, Abutalipova, 2015).

\section{Methods and Materials}

In the process of research, in accordance with its objectives, the following were used: theoretical methods; theoretical generalization of research results; empirical methods - study and generalization of existing experience in the field of designing clothing for people with disabilities, analysis of patent documents, observation, peer review, conversations with people with disabilities.

Over the years, the studies that have been conducted have led to the development of garments that have been customized to take into account the characteristics, manifestations and impact of several types of disabilities on the lives of those affected. Many people with disabilities live in constant stress with no other choice but to purchase clothes from regular stores. Typically, these outlets do not provide services and products to meet the needs of disabled customers. That is why designers and clothing manufacturers are considering creating adequate products from an ergonomic and aesthetic point of view, which would suit this particular category of buyers, according to the principles of universal design. Universal design (or inclusive design) refers to a wide range of ideas designed to produce buildings, create products and improve the environment, which are inherently accessible to older people, people without disabilities and people with disabilities (Curteza, Cretu, Macovei, Poboroniuc, 2014).

To ensure the psycho-emotional comfort of the disabled, it is proposed to create products that meet the requirements, which are part of the so-called «universal fashion».

The quality of life of people with disabilities can be improved by improving the design and functionality of clothing. Unlike the majority of the population, the specific requirements of persons with disabilities vary according to specific needs, which are driven by a specific need.

According to Rosstat, as of January 1, 2018, 12.1 million people of all disability groups were registered in Russia (8.2\% of the population of Russia).

Most of the disabled are classified in the second group of disability - 5.6 million people (since 2013, their number has decreased by 17.7\%), in the third group of disabilities - 4.4 million people (an increase of $7.3 \%$ over the past five years), 1.47 million people have the most difficult, first group of disabilities. 
Disabled people of the first and second groups are people with the most severe diseases, people with limited motor abilities (LMA). Most often, these diseases lead to the need to move in wheelchairs or using crutches, as well as to the need for specialized (adaptive) clothing with additional structural divisions, transforming elements or thermoregulatory inserts (Tukhbatullina, Dziyaudinova, 2020).

\section{Table 2. Requirements for designing clothing for LMA}

\begin{tabular}{|c|c|c|}
\hline Disabled group name & $\begin{array}{l}\text { Factors causing the greatest } \\
\text { inconvenience }\end{array}$ & Solutions \\
\hline 1st group & $\begin{array}{l}\text { - use of a wheelchair; } \\
\text { - sitting position of the body; } \\
\text { - the lower extremities are } \\
\text { immobilized; } \\
\text { - active movements of the upper half } \\
\text { of the body; }\end{array}$ & $\begin{array}{l}\text { - designing clothes with replaceable } \\
\text { cuffs on the forearm to avoid rapid } \\
\text { wear; } \\
\text { - use of elastic and knitted materials } \\
\text { and inserts from them; } \\
\text { - a high corset belt will help to keep } \\
\text { back, align your posture }\end{array}$ \\
\hline Group 2 & $\begin{array}{l}\text { - violations of coordination of } \\
\text { movements; } \\
\text { - weak hand motility; } \\
\text { - inability to fully control the } \\
\text { coordination of movements and } \\
\text { muscle strength; }\end{array}$ & $\begin{array}{l}\text { - simple and lightweight fasteners } \\
\text { (sticky fasteners, buttons, magnetic } \\
\text { fasteners); } \\
\text { - increase the entrance to the trousers } \\
\text { (position the zipper obliquely); } \\
\text { - wider leg and softer cut lines }\end{array}$ \\
\hline
\end{tabular}

The complexity of organizing the production of clothing for people with disabilities and, in particular, for disabled people-amputees and people with defects in the shoulder girdle lies, first of all, in the multi-purpose nature of the design process of products of the assortment group under consideration. On the one hand, these garments must meet aesthetic requirements and not emphasize the consumer's disability. On the other hand, to ensure the possibility of independent (or with minimal assistance) use of these clothes when removing and putting on, as well as the compliance of products with the physiological and hygienic needs of a person. Various causes of disability also determine different types of restrictions on a person's independent activity, therefore, it is necessary to study in more detail the forms of manifestation of diseases and what features of a person's lifestyle they provoke. Therefore, at the stage of designing and designing products, it is important to take into account the anatomical features of the figure of a wheelchair user, the change in the absolute values of dimensional characteristics relative to the standard typical figure (Gupta, 2011).

The need for specialized and adaptive clothing was identified in the 20th century. And since then, significant progress has been made in this area and key solutions have been found to the problems faced by wheelchair users.

The term «adaptive clothing» refers to a garment designed in view of medical functions for postoperative patients, persons with disabilities, the elderly, rehabilitation patients, children with special needs and adults with arthritis, and so on. D. The purpose of adaptive clothing is to have easy access to body parts (type and location of fasteners, pockets), to provide ease of movement and a comfortable fit. 
The analysis helped to identify an equally widespread problem, which consists in strong pressure on the spine, causing pain and discomfort in the back, which is caused by prolonged sitting. These inconveniences can not only provide discomfort, but also cause the appearance of various diseases (World Health Organization, 2002).

The solution to this problem is traditionally the use of orthopedic backs, corsets and pillows to provide support for the lumbar spine. But, the widespread use of inflatable technology in the manufacture of outerwear is applicable to create adaptive clothing that will provide a comfortable long-term stay in a wheelchair.

The technology for creating products with inflatable elements implies the manufacture of a chamber, which requires the use of synthetic materials:

- materials based on polyvinyl chloride;

- oxford;

- TPU;

- duspo.

The use of synthetic materials is necessary for the application of the high frequency welding technique, with the help of which the layers and joints of the products are soldered together. Another advantage is the outer covering of the inflatable bladder with an additional material that is more skin-friendly.

In the production of inflatable mattresses, a layer of softer material, pleasant to the skin - flock is added over PVC. The upper side of mattresses and beds is flocked, applying finely chopped textile fibers to the surface, which feel like velor to the touch.

\section{Results and Discussion}

The technology described above underlies the creation of "inflatable" clothing. The difference lies in the selection of materials and facilitation of technology, since in the production of mattresses, the primary task is strength, and in clothes - comfort and convenience. Thus, designers use only one layer of synthetic material, which allows the use of HFC induction welding. A local use of inflatable elements avoids air permeability problems (fig. 1).

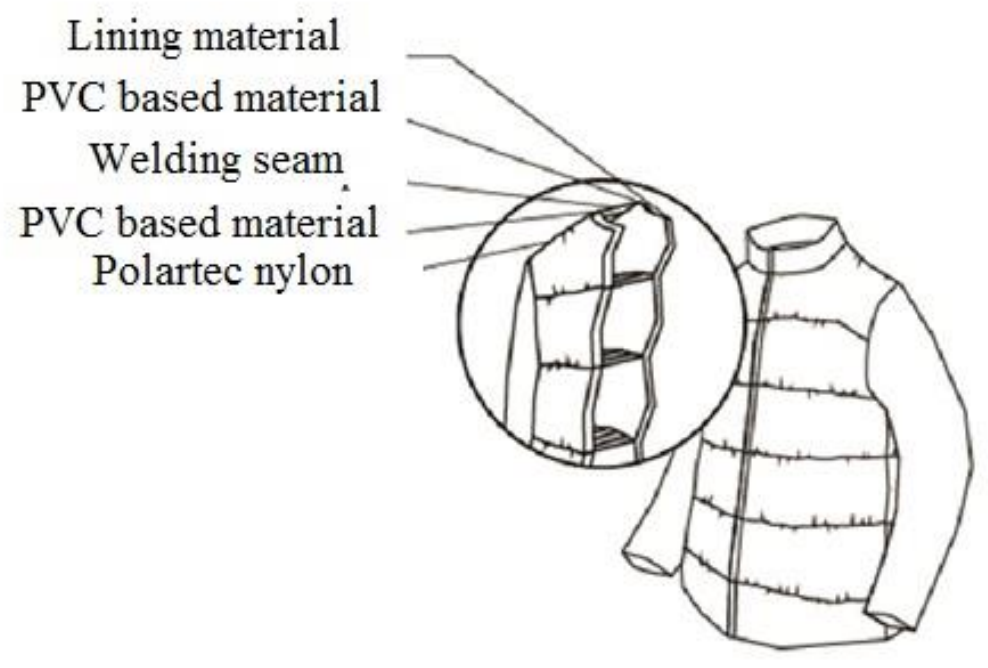

Figure 1. The structure of inflatable clothing items

The use of the considered inflatable elements in the creation of outerwear can be used to create support for the lumbar spine. Structural articulations on the back and front of the product, the 
volume of which can be changed by inflating these parts, repeating the principle of orthopedic backs, will help create a «corset» to support the upper torso, which will distribute the load on the spine (Fig. 2).

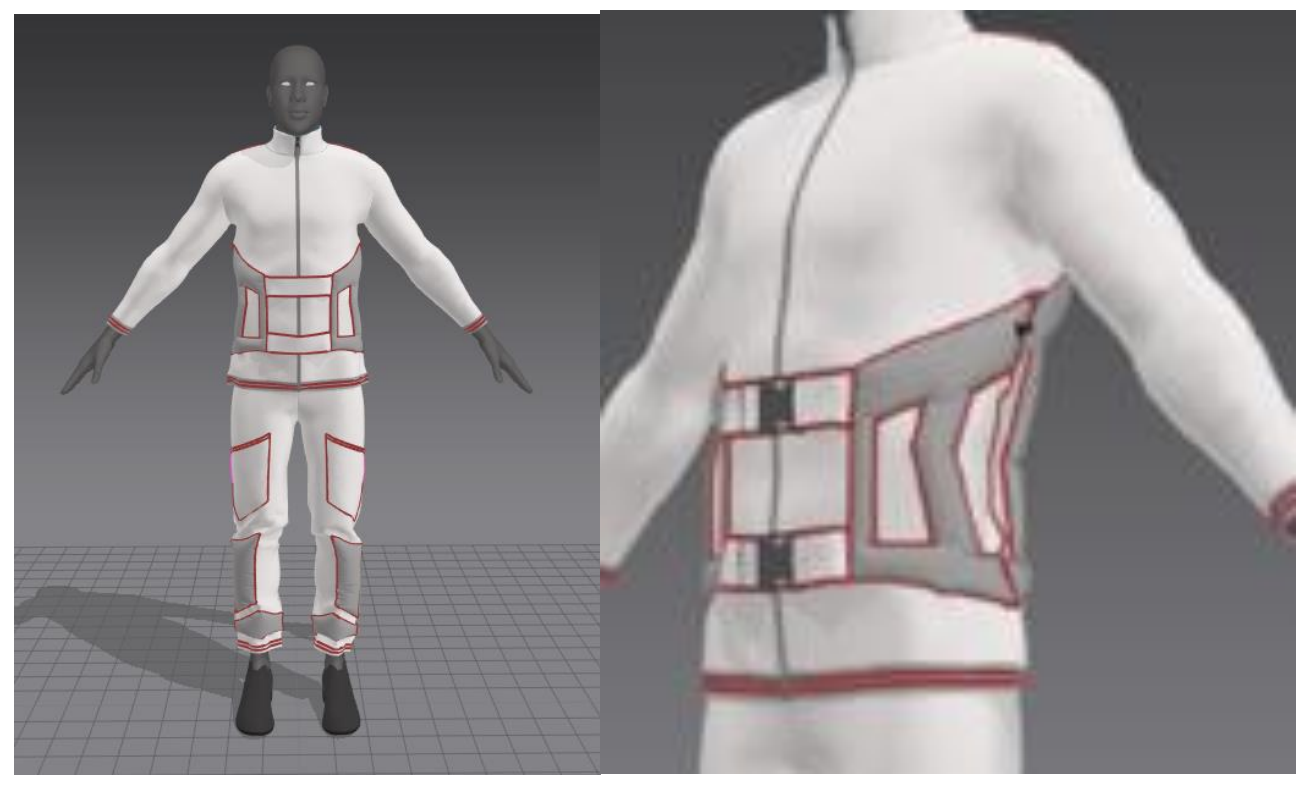

\section{Figure 2. Creation of a supporting corset using inflatable elements in clothing (own development)}

When designing shoulder products for wheelchair users, it is also important to take into account the discomfort created by the excessive length of the product. It is necessary to shorten the shelf to reduce the formation of unnecessary folds, as well as lengthen the sleeve along the line of the elbow cut.

Also, the transformation of these supporting elements, depending on the volume of air, will allow you to adjust the «inflatable corset» and use it when necessary.

The use of inflatable technology is also possible to solve the problem of temperature balance. Since the immobility of the lower limbs leads to rapid cooling, the use of special leg bags or capes has become widespread. When creating inflatable jackets and raincoats, air serves as an insulating element, which prevents the penetration of cold (Fig. 3).
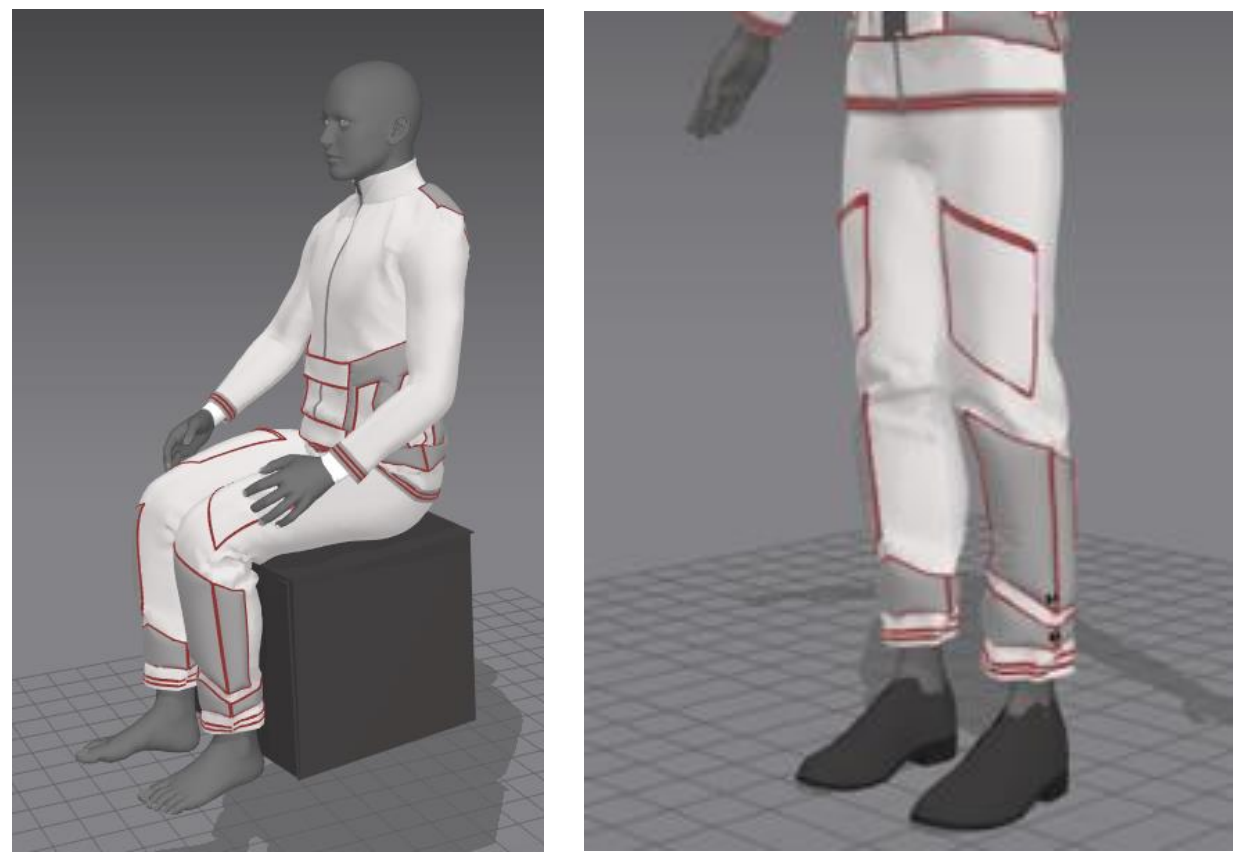


\section{Figure 3. Heat protection elements for the lower extremities (own development)}

That is why this technology, used in the development of a set of adaptive clothing, made it possible to create not only an «inflatable corset», but also heat-protective elements in the lower parts of the trousers, which also play the role of wind protection.

Since the greatest discomfort when using non-special clothing falls on the waist products, the development of this set also took into account the basic requirements for adaptive clothing for the «sitting» position:

- lengthening the back of the waist: for a natural fit, which will help to avoid the movement of the product down the back;

- shortening the length of the front: to reduce the volume of unwanted folds;

- offset and tilt of pockets for comfortable access.

The principles used in the development of this sample can be used in the design of other models of adaptive clothing. For female representatives, options for a set with a skirt can be developed. The location of air gaps in the lower part of the skirt will help maintain a comfortable microclimate in the lower part, preventing hypothermia of the individual's limbs. The solution to create a blanket skirt may be relevant. Such a product will be able to transform depending on the situation and take on the appearance of a part of a suit or an insulating element to cover a person not only in the area of the legs, but also in the area of the shoulder girdle. The location of the air space in different areas of the suit can also vary and adapt to the specific needs of a particular group of people with disabilities.

It is important to note that special textiles must have special functions and be made using fabrics with special properties (Suri, 2016). Since the list of requirements for clothing for people with disabilities naturally entails increased requirements for the textile materials used in the manufacture of products.

Thus, clothing should provide additional comfort at the functional and sensory levels, as well as at the psychological level. Textile products created for disabled people, in the end, turn out to be much more expensive than their usual counterparts, since their size and design do not correspond to standard products created for people without disabilities (Suri, 2016). Among other things, these products must have special functions and be made using fabrics with special properties, such as:

- certain tactile properties, especially when the product is addressed to people with sensitive skin;

- thermal comfort, which becomes paramount for people in wheelchairs or for those who spend a lot of time in bed;

- the ability to remove moisture created during perspiration (one of the most common problems), which implies optimal moisture absorption and air circulation.

\section{Conclusion}

When designing clothing for the disabled, designers focus on meeting needs at the social, physical and psychological level, taking into account a number of aspects (style, color and design), which will allow people with disabilities to express their taste and style preferences using clothing that meets their physiological requirements. Therefore, when developing adaptive clothing for disabled people, the designer faces a more difficult task, since it is necessary first of all to solve ergonomic problems, creating a product that meets all functional requirements, and only after that complement the product, meeting aesthetic requirements. The main goal of the research work is to create functional and relevant clothing for people with disabilities.

When performing the work, the requirements for clothing for disabled people were thoroughly studied, the concept of adaptive clothing was studied and the technology for developing inflatable clothing with transformation elements was considered. Based on the data studied, a set of adaptive 
clothing has been developed that provides maximum comfort and functionality. The design for this study of adaptive clothing for people with disabilities involved redesigning the linear dimensions of the back of the garment, as well as shortening the front pieces, which would contribute to a more comfortable sitting position. The location and depth of the pockets is adapted to the ergonomics of the seated person's body. Inflatable elements of adaptive clothing allow you to create an additional corset that helps to reduce physical stress on the spine, which plays a supporting role for the muscles of a sedentary disabled person. Inflatable elements in the lower part of the suit create a heat and wind protection effect. Adaptive clothing, developed taking into account the studied requirements and based on the recommendations described in the article, will contribute to a more comfortable physical and emotional stay of people with disabilities.

\section{References}

Bolgitskaya, A.N. (2014). Disabled person and society. Monitoring of public opinion July - August 2014, 4(122). Retrieved from: https://cyberleninka.ru/article/n/invalidy-i-obschestvo/viewer

Curteza, A., Cretu, V., Macovei, L., Poboroniuc, M. (2014). Designing funcional clothes for persons with locommotor disabilities. AUTEX Research Journal, 14(4).

Gupta, D. (2011). Functional Clothing - definition and classification. Indian Journal of Fiber and Textile Research, 326.

Krasnova, O. (2011). Introduction to the psychology of disability. Moscow: MPSI, MODEK.

Safina, L.A., Tukhbatullina, L.M., Khammatova, V.V., Abutalipova, L.N. (2015). Costume Design: A Tutorial. Moscow: INFRA-M.

Suri, P. (2016). Clothing needs assessment for wheelchair users. Kent State University.

Tukhbatullina, L.M., Dziyaudinova, T.M. (2020). Features of clothing design for people with disabilities. Kostyumologiya, $1 . \quad$ Retrieved from: https://kostumologiya.ru/PDF/04TLKL120.pdf

World Health Organization. (2002). World Health Survey. Geneva, 2002-2004. Retrieved from: http://www.who.int/healthinfo/survey/en 